\title{
Local control of striatal dopamine release
}

\author{
Roger Cachope ${ }^{1,2}$ and Joseph F. Cheer ${ }^{1,3} *$ \\ 'Department of Anatomy and Neurobiology, University of Maryland School of Medicine, Baltimore, MD, USA \\ ${ }^{2} \mathrm{CHDI}$ Foundation, Los Angeles, CA, USA \\ ${ }^{3}$ Department of Psychiatry, University of Maryland School of Medicine, Baltimore, MD, USA
}

\section{Edited by:}

Anton Ilango, National Institutes of Health (NIH), USA

\section{Reviewed by:}

Kate M. Wassum, University of

California Los Angeles, USA

Stephan Lammel, Stanford

University, USA

*Correspondence:

Joseph F. Cheer, Department of Anatomy and Neurobiology,

University of Maryland School of Medicine, 20 Penn Street, HSF I,

Room 280J, Baltimore, MD 21201, USA

e-mail: jchee001@umaryland.edu
The mesolimbic and nigrostriatal dopamine (DA) systems play a key role in the physiology of reward seeking, motivation and motor control. Importantly, they are also involved in the pathophysiology of Parkinson's and Huntington's disease, schizophrenia and addiction. Control of DA release in the striatum is tightly linked to firing of DA neurons in the ventral tegmental area (VTA) and the substantia nigra (SN). However, local influences in the striatum affect release by exerting their action directly on axon terminals. For example, endogenous glutamatergic and cholinergic activity is sufficient to trigger striatal DA release independently of cell body firing. Recent developments involving genetic manipulation, pharmacological selectivity or selective stimulation have allowed for better characterization of these phenomena. Such termino-terminal forms of control of DA release transform considerably our understanding of the mesolimbic and nigrostriatal systems, and have strong implications as potential mechanisms to modify impaired control of DA release in the diseased brain. Here, we review these and related mechanisms and their implications in the physiology of ascending DA systems.

Keywords: dopamine, acetylcholine, glutamate, striatum, optogenetics, axonal release, volume transmission

\section{INTRODUCTION: ROLE OF DA IN MOTOR AND LIMBIC FUNCTION}

Dopamine (DA) plays a critical role in the organization of reward-seeking behavior and motor responses (Joshua et al., 2009; Schultz, 2013). Through the mesolimbic and nigrostriatal DA systems, the forebrain receives dopaminergic input that modulates a range of functionally distinct structures, such as the basal ganglia and cerebral cortex (Björklund and Dunnett, 2007; Tritsch and Sabatini, 2012). The mesolimbic system is formed by dopaminergic neurons located in the VTA and their projections to the nucleus accumbens (NAc), cortex, amygdala and hippocampus, which participate in the configuration of reward-seeking behaviors (Björklund and Dunnett, 2007; Stuber et al., 2012; Nieh et al., 2013). The nigrostriatal system has its origin in the substantia nigra pars compacta $(\mathrm{SNc})$ and projects preferentially to the dorsolateral domains of the striatum, having a more defined role in the organization of motor plans (Groenewegen, 2003; DeLong and Wichmann, 2007). Such functional distinction at the level of the striatum seems to have structural and molecular correlates on DA neurons from the SNc (Henny et al., 2012; Schiemann et al., 2012). Additional to these functional implications, dopaminergic transmission is compromised in a variety of neurological conditions such as schizophrenia, Huntington's and Parkinson's disease, drug addiction and obsessive-compulsive disorder, among others (DeLong and Wichmann, 2007; Money and Stanwood, 2013).

The striatum is the main input nucleus of the basal ganglia, and DA modulates how this input is processed (Calabresi et al., 1997; Centonze et al., 2001; Tritsch and Sabatini, 2012).
However, in contrast to the traditional view of inter-neuronal chemical excitatory synaptic transmission in which structural and functional specializations are observed at the postsynaptic domains, striatal dopaminergic transmission does not always require such level of postsynaptic structural specialization (Rice and Cragg, 2008; Fuxe et al., 2012). Instead, release occurs in a diffuse manner, DA receptors are extrasynaptic and ultrastructural studies on the extension and density of DA neuron axonal arborization in the striatum point to broad, intricate projections that cover vast areas (Pickel et al., 1981; Smith et al., 1994; Moss and Bolam, 2008; Matsuda et al., 2009). This diffusely spread mode of transmission (in contrast to localized, highly spatially restricted communication), is termed "volume transmission", and is a feature of a number of transmitters such as acetylcholine, norepinephrine, DA and serotonin (Taber and Hurley, 2014). Volume transmission of DA is, however, not exclusive to the striatum and it has its own particularities through different areas (Rice and Cragg, 2008; Fuxe et al., 2012; Martin and Spühler, 2013; Taber and Hurley, 2014). DA as a volume transmitter in the striatum is thought to exert a widespread modulatory influence on excitatory-glutamatergic-transmission arriving from the cortex, basolateral amygdala (BLA), and ventral hippocampus (vHipp; Britt et al., 2012); or on inhibitory-GABAergictransmission incoming from areas such as VTA (Van Bockstaele and Pickel, 1995) and ventral pallidum (Churchill and Kalivas, 1994).

DA modulation of incoming transmission to the striatum plays a key role in the functional expression of reward-seeking behaviors and motor control. Such functions exhibit some stratification 
within the striatum (Threlfell and Cragg, 2011). For example, dorso-medial and dorso-lateral areas are predominantly involved in motor control, while ventro-medial segments are mostly involved in the expression of reward processing, motivation and salience (Groenewegen, 2003; Voorn et al., 2004; Kreitzer and Berke, 2011; Stuber et al., 2012). Concurrently, cortico-striatal projections also exhibit a stratified distribution in which the motor and cingulate cortices form the primary input to the dorsolateral striatum, while prefrontal and prelimbic cortices project mainly to ventro-medial areas of the striatum (Voorn et al., 2004). Phenomena responsible for regulation of striatal DA release can be VTA/SNc driven, or locally acting, at the striatal level. This latter possibility has long been reported, still attracts considerable attention in terms of mechanistic characterization (Cachope et al., 2012; Threlfell et al., 2012) and is considered as an opportunity for functionally-segregated intervention (Threlfell and Cragg, 2011).

\section{MULTIPLICITY OF MECHANISMS IN THE CONTROL OF DOPAMINE RELEASE}

Through what are now seminal papers, Wolfram Schultz et al. demonstrated that firing of DA neurons in the midbrain increases in response to rewarding stimuli in non-human primates (Schultz et al., 1997; Schultz, 1998), while functional imaging studies in humans point to a similar increase in cellular activity (D'Ardenne et al., 2008), suggesting correspondence with Schultz's group reports. Interestingly, it was recently described that VTA GABAergic neurons also encode reward expectation (Cohen et al., 2012). Recordings of DA neurons from the VTA or SNc areas in rodents exhibit slow, tonic firing rates that periodically switch to a high frequency events (Grace and Bunney, 1984a,b). Thus, low levels of DA release have been correlated with low frequency firing rate of DA neurons, while corresponding enhancement in striatal DA release occurs in response to high frequency firing rates (Kawagoe et al., 1992). These findings have sculpted the traditional view of striatal DA release being determined by the rate of neuronal firing of the DA neuron somatas located in either VTA or SNc. However, besides this dominant mechanism of control of DA release, local factors such as reuptake, autoreceptor-dependent modulation, and termino-terminal control exist and are recognized to play a prominent role, independently of VTA/SNc firing rate.

DA neurons projecting to the striatum establish prominent axonal trees at their destination. The volume transmission feature of striatal DA implies that a considerable amount of control is required in terms of uptake and/or negative feedback on future release events. In reaching this goal, two key mechanisms are DA transporter activity (DAT) and D2-like presynaptic autoreceptor activity. DAT activity is thought to limit the radius of DA activity (Rice and Cragg, 2008) and, by doing so, restricts activation of DA receptors (reviewed in Rice et al., 2011). In a similar manner, it is known that blockade of D2-like DA receptors in slices leads to increased DA release in response to repetitive electrical stimulation (Limberger et al., 1991; Patel et al., 1992). This effect, however, is not manifest when single pulse stimulation is used (Limberger et al., 1991; Patel et al., 1992), suggesting that there is not sufficient DA tone elicited by a single pulse to be displaced by the antagonist. Importantly, changes in D2 receptor levels and their subsequent activation are thought to play a prominent role in several neurological conditions in which DA levels are altered (Ford, 2014).

\section{LOCAL STRIATAL CONTROL OF DOPAMINE RELEASE GLUTAMATERGIC TRANSMISSION}

Excitatory glutamatergic activity in the striatum originates mainly from frontal cortex, midline and intralaminar thalamus, basal amygdala, and hippocampus (reviewed in Sesack and Grace, 2010; Stuber et al., 2012). Additionally, DA terminals release glutamate (Sulzer et al., 1998; Joyce and Rayport, 2000; Sulzer and Rayport, 2000; Chuhma et al., 2004; Dal Bo et al., 2004; Chuhma et al., 2009; Hnasko et al., 2010), and this has recently been demonstrated by way of selective optogenetic stimulation of DA terminals (Stuber et al., 2010). However, this last report demonstrates that such possibility exists only in DA terminals that reach the NAc, not the dorsal striatum. Still, some debate prevails as to this feature not being present in the adult brain (BérubéCarrière et al., 2009; Moss et al., 2011), or being as widespread as initially thought (Stuber et al., 2010; for a review, see Broussard, 2012).

Evidence on the potential role of glutamate as a form of local control of DA release in the striatum has long been reported (Imperato et al., 1990; Cheramy et al., 1991; Krebs et al., 1991; Desce et al., 1992) and both ionotropic and metabotropic glutamate receptors (iGluR; mGluR, respectively) have been implicated. However, most of the initial studies were performed in vivo using brain microdialysis as the measuring technique to assess DA levels as well as for local administration of glutamate receptor ligands. Such findings were of course influenced by slow temporal resolution and the effects of the ligand in a complex circuit, among other factors, making a mechanistic interpretation difficult. In vitro experimental designs, on the other hand, allowed for more direct mechanistic description while still not directly addressing whether results were equivalent to intact-tissue conditions. These distinct experimental conditions might account for what, at the time, were apparent contradictory results. Initial in vitro explorations in slices and synaptosomes accounted not only for glutamate, but for a range of neurotransmitters that could affect striatal DA release locally, including acetylcholine, GABA, glycine and opiates (reviewed in Chesselet, 1984). However, further in vivo experiments in freely moving rats were still non conclusive; i.e., activation of AMPA receptors by exogenous ligands led to a decrease in DA release, while an increase was evident only in response to the application of NMDA receptor ligands at high concentrations (Imperato et al., 1990). Blocking uptake of endogenous release, in turn, elevated DA release in a way that was sensitive to the application of either NMDA or AMPA antagonists, suggesting the involvement of both receptor types in that response (Segovia et al., 1997). Similarly, electrical stimulation of the prefrontal cortex, a putative glutamatergic input to striatum, as well as local application of kainate or NMDA increased DA release (Cheramy et al., 1991; Krebs et al., 1991). Development of electrochemical techniques, however, greatly contributed to the clarification of these mechanisms. The use of fast-scan cyclic voltammetry (FSCV) for the detection of DA in vitro allowed for 
better temporal resolution which was less influenced by circuit adaptive responses in the mid-term scale (minutes), which could potentially influence DA readout. Under those conditions, bath application of kainate, AMPA or NMDA elicited inhibition of DA release (Wu et al., 2000; Kulagina et al., 2001; Avshalumov et al., 2003). Moreover, electron microscopy studies were not able to demonstrate labeling of iGluRs in striatal DA terminals (Bernard et al., 1997; Bernard and Bolam, 1998). The lack of expression of iGluRs on DA terminals suggests that iGluRmediated modulation of DA release relates to a more complex process; which may underlie interactions between multiple cellular types and/or chemical mediators. This issue, raised and investigated by Rice's group led to the identification of $\mathrm{H}_{2} \mathrm{O}_{2}$ as a key molecule in the iGluR-mediated decrease of DA release (Avshalumov et al., 2000, 2003, 2008; Avshalumov and Rice, 2003). This model describes how glutamatergic activity on ionotropic receptors in medium spiny neurons (MSNs) triggers production and release of $\mathrm{H}_{2} \mathrm{O}_{2}$, which in turn diffuses to adjacent DA terminals and promotes opening of $\mathrm{K}_{\mathrm{ATP}}$ channels leading to reduction of DA release (Avshalumov et al., 2008).

In contrast to iGluRs, labeling of mGluRs has been reported in presynaptic profiles identified as DA axons (Paquet and Smith, 2003). Moreover, blocking glutamate uptake, or high-frequency stimulation of the cortico-striatal pathway modulates DA release, in a mGluR-dependent fashion followed by modulation of $\mathrm{Ca}^{++}$activated potassium channels (Zhang and Sulzer, 2003). Altogether, the existent evidence points to mGluR-mediated direct action on DA terminals, and a second MSN-mediated mechanism involving iGluR- $\mathrm{H}_{2} \mathrm{O}_{2}$ signaling.

\section{CHOLINERGIC TRANSMISSION}

In contrast to striatal glutamatergic activity, which originates mainly from inputs to the striatum, sources of striatal acetylcholine release are mostly from cholinergic interneurons (CINs) that account for about 2-5\% of all striatal neurons (Descarries et al., 1997; Descarries and Mechawar, 2000). Additional to CINs, a recent report shows that brainstem-based cholinergic neurons send terminals to the striatum in a topographic fashion with their origin (Dautan et al., 2014). In spite of their low numbers, CINs establish prominent and intricate axonal projections that configure an extensive planar neurotransmission system (Descarries et al., 1997; Descarries and Mechawar, 2000). Electrophysiological characterization shows that CINs are tonically active neurons that fire at a relatively low rate of about 5-10 Hz (Wilson et al., 1990; Aosaki et al., 1995). This rate, however, as in the case of DA neurons, encodes behaviorally relevant reward-related events (Apicella et al., 1991, 2011; Aosaki et al., 1994, 1995; Shimo and Hikosaka, 2001; Morris et al., 2004).

Target receptors of cholinergic activity in the striatum are both of nicotinic and muscarinic types (nAChR and mAChR, respectively). While $\mathrm{mAChRs}$ are seven trans-membrane domain G-protein coupled receptors, nAChRs consist of five subunits arranged as homomers or heteromers that, in mammals, are formed by subfamilies II $(\alpha 7)$ and III $(\alpha 2-6, \beta 2-4)$ (Le Novère et al., 2002). Particularly, striatal DA axons express a high density of $\alpha 4, \alpha 5, \alpha 6, \beta 2$ and $\beta 3$ subunits in an arrangement of two $\alpha \beta$ pairs that could be $\alpha 4-\beta 2$ and/or $\alpha 6-\beta 2$ and/or $\alpha 4-\beta 4$, plus a fifth subunit that can be $\alpha 5$ or $\beta 3$ (Champtiaux et al., 2003; reviewed in Threlfell and Cragg, 2011). Additionally, the $\beta 2$ subunit is expressed on striatal DA axons (Jones et al., 2001) and is included in all nAChRs at these terminals. This characterization is functionally relevant because some segregation exists in which predominance of different $\alpha$ subunits occurs between dorsolateral striatum and the NAc. More specifically, a significant amount of work has shown that $\alpha 4$ (non- $\alpha 6)$-nAChRs play a prominent role in dorsal striatum, while $\alpha 4 \alpha 6-n A C h R s$ are dominant in NAc (Exley et al., 2008, 2011, 2012). Given the distinct functional role of the dorsolateral and the ventromedial striatum, it has been proposed that such differences could be taken into account as a substrate for region-specific intervention (Threlfell and Cragg, 2011).

mAChRs, in turn, are classified in two groups according to their coupling to either $G_{s}\left(M_{1}, M_{3}, M_{5}\right)$ or $G_{i}\left(M_{2}, M_{4}\right)$ subunits of $G$ proteins, with $\mathrm{M}_{2}$ and $\mathrm{M}_{4}$ predominantly expressed in CINs (Yan and Surmeier, 1996). In a similar way to what has been described for nAChRs, mAChRs exhibit some dorso-ventral gradient in their ability to regulate DA release. While $M_{2} / M_{4}$ receptors are necessary for such regulation in the dorsal striatum, M4 is prevalent in the NAc (Threlfell et al., 2010). Additionally, expression of $\mathrm{M}_{5}$ receptors has been reported in nigrostriatal DA neurons, although their pattern of expression on striatal DA terminals and subsequent potential role in local control of DA release remains unclear (reviewed in Threlfell and Cragg, 2011; Zhang and Sulzer, 2012).

Involvement of presynaptic cholinergic receptors on DA regulation was inferred early, mainly from experiments describing increase of DA release in response to AChR activation in slices or synaptosomes (Giorguieff et al., 1976, 1977; Wonnacott et al., 1989; Rapier et al., 1990). In a similar way to what occurred with the characterization of glutamatergic-dependent DA modulation, transition to electrochemical methods to quantify DA allowed for a better temporal resolution. Importantly, FSCV has been critical in determining a high dependence of DA release on stimulation frequency under the effect of nicotine. More specifically, in a striatal slice, the maximum peak of DA release does not change significantly through different frequencies $(5,10,25,50 \mathrm{~Hz})$ of electrical stimulation. However, in the presence of nicotine or the nAChR antagonist mecamylamine, DA release at low frequencies is decreased, while at high frequencies release is enhanced (Rice and Cragg, 2004).

While electrical stimulation combined with pharmacological and genetic manipulations have produced a wealth of information on cholinergic control of DA release (Giorguieff et al., 1977; Cheramy et al., 1991; Krebs et al., 1991; Desce et al., 1992; Tremblay et al., 1992; Chéramy et al., 1996; Schmitz et al., 2003; Zhang and Sulzer, 2003, 2012; Exley and Cragg, 2008; Exley et al., 2011; reviewed by Cragg, 2006; Rice et al., 2011; Threlfell and Cragg, 2011; Zhang and Sulzer, 2012), the advent of optogenetics offered the previously unseen possibility of selective control of CINs. This would allow inducing AChR activation by means of endogenous release of $\mathrm{ACh}$, obtained by 
selective stimulation of striatal CINs. Taking advantage of in vitro slices, electrochemistry, and optogenetics, both the laboratory of Stephanie Cragg (Threlfell et al., 2012) and ours (Cachope et al., 2012) were interested in characterizing changes in striatal DA levels in response to endogenous AChR activation. Interestingly, both research groups were advancing on characterizing similar phenomena in functionally different striatal areas, showing how endogenous release of ACh directly triggers DA release in the dorsal striatum and the NAc, respectively. Additionally to demonstrating how selective activation of CINs is enough to trigger DA release in striatum and NAc, respectively, both reports confirmed the role of nAChRs and mAChRs in modulating such output. Moreover, Cragg's report very nicely unveiled circuital mechanisms by which thalamic input synchronizes CIN firing, subsequently promoting DA release (Threlfell et al., 2012). Our experiments focused instead on the possibility of CINs-triggered DA release in vivo (Cachope et al., 2012). Consistently with the in vitro data, optogenetic stimulation of CINs in the anesthetized mouse was sufficient to trigger elevation of DA concentrations in the NAc. Also, following Sabatini's group's report regarding the ability of CINs to evoke glutamatergic responses (Higley et al., 2011), we showed that AChevoked DA release is sensitive to AMPA blockers (Cachope et al., 2012).

In the case of mAChRs, they can also locally modulate DA release in the striatum. In vitro experiments with FSCV show how a wide range $\mathrm{mAChR}$ antagonist (oxotremorine) decreases DA release evoked by single pulse electrical stimulation, but enhances
DA levels in response to train stimulation (Threlfell et al., 2010). A similar effect was observed using selective optogenetic stimulation, in which single pulse optical stimulation did not affect DA release, but instead 5 and $10 \mathrm{~Hz}$ stimulation enhanced DA release under application of the $\mathrm{mAChR}$ antagonist scopolamine (Cachope et al., 2012; Threlfell et al., 2012).

A complex interaction between diverse neurotransmission and neuromodulatory systems takes place in the control of striatal DA release. Although we have focused on the effect of glutamatergic and cholinergic systems, a handful other receptors have been identified as able to alter striatal DA levels; including GABA, cannabinoid, purinergic and opioid. Interestingly (and, up to some point expected), the possibilities for diversity on this local control are dependent on the type of receptor, not just the type of transmitter/modulator being released. Both in the case of glutamate and acetylcholine, different receptors lead to distinct and even opposite effects. As illustrated in Figure 1, mGluR activation on DA terminals and iGluR activation on MSNs result both in modulation of $\mathrm{K}$ conductances decreasing DA release. In contrast, activation of nAChRs on DA terminals leads to increased DA release, while activation of $\mathrm{mAChR}$ autoreceptors expectedly result in decreased DA release. More importantly, all these results demonstrate that firing rate at the VTA and $\mathrm{SNc}$ does not entirely determine striatal DA output, leaving enough room for control mechanisms driven by input from other areas (glutamatergic), as well as by interneurons (cholinergic), which might exert considerable impact on it.

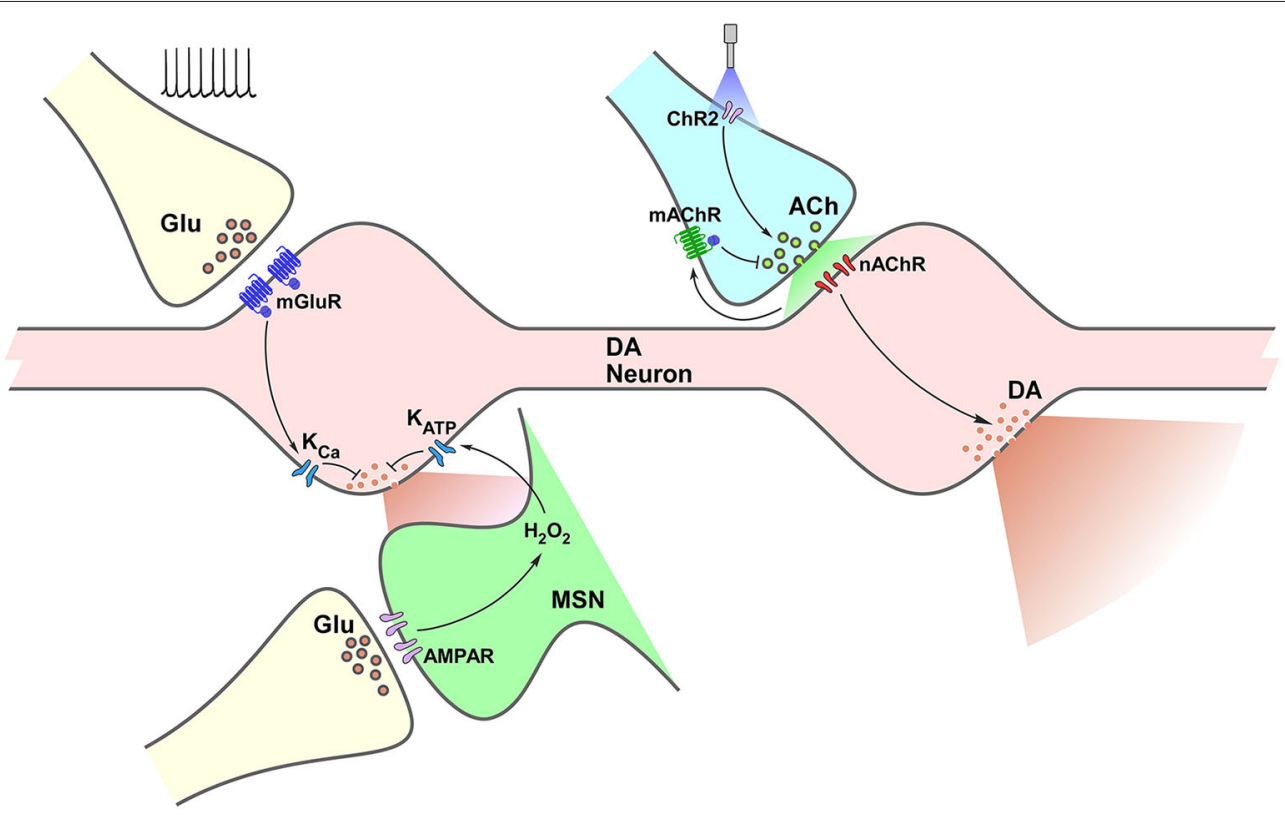

FIGURE 1 | Termino-terminal control of dopamine (DA) release in the striatum. Model diagram of glutamatergic (left side of graph) and cholinergic (right side of graph) local influences on striatal DA release. Electrically-evoked glutamate release activates $\mathrm{mGluRs}$ located on dopaminergic varicosities increasing $\mathrm{Ca}^{++}$-sensitive $\mathrm{K}$ channels $\left(\mathrm{K}_{\mathrm{Ca}}\right)$ conductance, which leads to reduction of DA release. Activation of iGluRs on MSNs elevates production of
$\mathrm{H}_{2} \mathrm{O}_{2}$, which diffuses to DA varicosities enhancing ATP-sensitive $\mathrm{K}$ channels (KATP) conductance reducing DA release. Optogenetic selective activation of cholinergic interneurons (CINs) through channelrhodopsin (ChR2) triggers ACh release, increasing $n A C h R$ activation on DA varicosities, triggering DA release. Activation of mAChRs on cholinergic terminals decreases ACh release and further nAChR activation, which would result in decreased DA release. 


\section{CONCLUDING REMARKS}

The role of DA in essential behaviors such as reward-seeking, motivation and motor control has been extensively studied. Regulation of DA release at both the dorso-lateral striatum and the NAc is considered to be mainly the consequence of changes in firing rate at the level of DA somata in the SNc and the VTA, correspondingly. Local control at the level of the striatum has been traditionally linked to DA reuptake and to feedback control on DA release through activation of D2 autoreceptors. However, reports on termino-terminal control of DA release, although scarce decades ago provided key findings in understanding a more complex control system than the one defined just by firing rate at DA neuronal somata. To date, the influence of non-DA striatal terminals on striatal DA release has been explored in a variety of experimental conditions, including synaptosomes, in vitro slices and in vivo preparations. Not only pharmacological, but genetic, optogenetic, electrophysiological and electrochemical strategies have been used to unveil the localization, role, extent and functional impact of such local influences. Glutamatergic and cholinergic systems have attracted the most attention so far. Still, although highly characterized in terms of types of receptors and neurotransmitters involved, there is not enough evidence on the functional impact of these forms of regulation in the behavioral setting. CINs modify their firing rate in animals subject to behavioral tasks encoding reward delivery as a decrease in firing rate, following a mild increase in frequency of firing (Apicella et al., 1991, 2011; Aosaki et al., 1994; Shimo and Hikosaka, 2001; Morris et al., 2004). Also, a recent report shows a differential role of DA neurons modulating CINs firing in dorsal striatum and NAc (Chuhma et al., 2014). However, there is no clarity as to how prominent all those interactions are in terms of their ability to affect DA release, and even less is known about the role of such variations, if they might impact behavior, or if DA transmission is otherwise still VTA- and SNc-driven.

One of the main strategies to fully develop yet is the potential of targeting these modulation systems to affect striatal DA release in conditions such as Parkinson's disease, schizophrenia, addiction, Huntington's disease, in which DA levels have been reported to be altered. As already outlined by Threlfell and Cragg (2011), modulating the striatal cholinergic system through subunit-specific modulation of $\mathrm{nAChR}$ and $\mathrm{mAChR}$ promises to be a useful approach. Temporal dynamics are a critical feature of inter-neuronal transmission. Behavioral events have, for example, phasic changes in striatal DA levels as correlates in the limbic and motor areas (O'Neill and Fillenz, 1985; Schultz, 2007a,b; Joshua et al., 2009). A significant proportion of therapeutic strategies are based on ligands that exert a sustained effect on neurotransmitter receptors, cancelling such changes over time. While DA neuron somata drive phasic changes in DA release, termino-terminal control might be seen as a mechanism that allows for fine regulation over that main drive, still preserving most of the temporal dynamics.

\section{REFERENCES}

Aosaki, T., Kimura, M., and Graybiel, A. M. (1995). Temporal and spatial characteristics of tonically active neurons of the primate's striatum. J. Neurophysiol. 73, 1234-1252.
Aosaki, T., Tsubokawa, H., Ishida, A., Watanabe, K., Graybiel, A., and Kimura, M. (1994). Responses of tonically active neurons in the primate's striatum undergo systematic changes during behavioral sensorimotor conditioning. J. Neurosci. 14, 3969-3984.

Apicella, P., Ravel, S., Deffains, M., and Legallet, E. (2011). The role of striatal tonically active neurons in reward prediction error signaling during instrumental task performance. J. Neurosci. 31, 1507-1515. doi: 10.1523/jneurosci.4880-10. 2011

Apicella, P., Scarnati, E., and Schultz, W. (1991). Tonically discharging neurons of monkey striatum respond to preparatory and rewarding stimuli. Exp. Brain Res. 84, 672-675. doi: 10.1007/bf00230981

Avshalumov, M. V., Chen, B. T., Marshall, S. P., Peña, D. M., and Rice, M. E. (2003). Glutamate-dependent inhibition of dopamine release in striatum is mediated by a new diffusible messenger, H2O2. J. Neurosci. 23, 2744-2750. doi: 10.1073/pnas. 1834314100

Avshalumov, M. V., Chen, B. T., and Rice, M. E. (2000). Mechanisms underlying $\mathrm{H}(2) \mathrm{O}(2)$-mediated inhibition of synaptic transmission in rat hippocampal slices. Brain Res. 882, 86-94. doi: 10.1016/s0006-8993(00)02835-3

Avshalumov, M., Patel, J., and Rice, M. (2008). AMPA receptor-dependent H 2 O 2 generation in striatal spiny neurons, but not dopamine axons: one source of a retrograde signal that can inhibit dopamine release. J. Neurophysiol. 100, 15901601. doi: 10.1152/jn.90548.2008

Avshalumov, M., and Rice, M. (2003). Activation of ATP-sensitive K+ (KATP) channels by $\mathrm{H} 2 \mathrm{O} 2$ underlies glutamate-dependent inhibition of striatal dopamine release. Proc. Natl. Acad. Sci. U S A 100, 11729-11734. doi: 10. 1073/pnas. 1834314100

Bernard, V., and Bolam, J. P. (1998). Subcellular and subsynaptic distribution of the NR1 subunit of the NMDA receptor in the neostriatum and globus pallidus of the rat: co-localization at synapses with the GluR2/3 subunit of the AMPA receptor. Eur. J. Neurosci. 10, 3721-3736. doi: 10.1046/j.1460-9568.1998. 00380.x

Bernard, V., Somogyi, P., and Bolam, J. P. (1997). Cellular, subcellular and subsynaptic distribution of AMPA-type glutamate receptor subunits in the neostriatum of the rat. J. Neurosci. 17, 819-833.

Bérubé-Carrière, N., Riad, M., Dal Bo, G., Lévesque, D., Trudeau, L.-E., and Descarries, L. (2009). The dual dopamine-glutamate phenotype of growing mesencephalic neurons regresses in mature rat brain. J. Comp. Neurol. 517, 873891. doi: $10.1002 / \mathrm{cne} .22194$

Björklund, A., and Dunnett, S. B. (2007). Dopamine neuron systems in the brain: an update. Trends Neurosci. 30, 194-202. doi: 10.1016/j.tins.2007.03.006

Britt, J. P., Benaliouad, F., McDevitt, R. A., Stuber, G. D., Wise, R. A., and Bonci, A. (2012). Synaptic and behavioral profile of multiple glutamatergic inputs to the nucleus accumbens. Neuron 76, 790-803. doi: 10.1016/j.neuron.2012. 09.040

Broussard, J. I. (2012). Co-transmission of dopamine and glutamate. J. Gen. Physiol. 139, 93-96. doi: 10.1085/jgp.201110659

Cachope, R., Mateo, Y., Mathur, B. N., Irving, J., Wang, H., Morales, M., et al. (2012). Selective activation of cholinergic interneurons enhances accumbal phasic dopamine release: setting the tone for reward processing. Cell Rep. 2, 33 41. doi: 10.1016/j.celrep.2012.05.011

Calabresi, P., Pisani, A., Centonze, D., and Bernardi, G. (1997). Synaptic plasticity and physiological interactions between dopamine and glutamate in the striatum. Neurosci. Biobehav. Rev. 21, 519-523. doi: 10.1016/s0149-7634(96) 00029-2

Centonze, D., Picconi, B., Gubellini, P., Bernardi, G., and Calabresi, P. (2001). Dopaminergic control of synaptic plasticity in the dorsal striatum. Eur. J. Neurosci. 13, 1071-1077. doi: 10.1046/j.0953-816x.2001.01485.x

Champtiaux, N., Gotti, C., Cordero-Erausquin, M., David, D. J., Przybylski, C., Léna, C., et al. (2003). Subunit composition of functional nicotinic receptors in dopaminergic neurons investigated with knock-out mice. J. Neurosci. 23, 78207829.

Chéramy, A., Godeheu, G., L’Hirondel, M., and Glowinski, J. (1996). Cooperative contributions of cholinergic and NMDA receptors in the presynaptic control of dopamine release from synaptosomes of the rat striatum. J. Pharmacol. Exp. Ther. 276, 616-625.

Cheramy, A., Kemel, M. L., Gauchy, C., Desce, J. M. J., Galli, T., Barbeito, L., et al. (1991). Role of excitatory amino acids in the direct and indirect presynaptic regulation of dopamine release from nerve terminals of nigrostriatal dopaminergic neurons. Amino Acids 1, 351-363. doi: 10.1007/bf00814004 
Chesselet, M. F. (1984). Presynaptic regulation of neurotransmitter release in the brain: facts and hypothesis. Neuroscience 12, 347-375. doi: 10.1016/03064522(84)90058-7

Chuhma, N., Choi, W. Y., Mingote, S., and Rayport, S. (2009). Dopamine neuron glutamate cotransmission: frequency-dependent modulation in the mesoventromedial projection. Neuroscience 164, 1068-1083. doi: 10.1016/j.neuroscience. 2009.08.057

Chuhma, N., Mingote, S., Moore, H., and Rayport, S. (2014). Dopamine neurons control striatal cholinergic neurons via regionally heterogeneous dopamine and glutamate signaling. Neuron 81, 901-912. doi: 10.1016/j.neuron.2013.12.027

Chuhma, N., Zhang, H., Masson, J., Zhuang, X., Sulzer, D., Hen, R., et al. (2004). Dopamine neurons mediate a fast excitatory signal via their glutamatergic synapses. J. Neurosci. 24, 972-981. doi: 10.1523/jneurosci.4317-03.2004

Churchill, L., and Kalivas, P. W. (1994). A topographically organized gammaaminobutyric acid projection from the ventral pallidum to the nucleus accumbens in the rat. J. Comp. Neurol. 345, 579-595. doi: 10.1002/cne.903450408

Cohen, J. Y., Haesler, S., Vong, L., Lowell, B. B., and Uchida, N. (2012). Neurontype-specific signals for reward and punishment in the ventral tegmental area. Nature 482, 85-88. doi: 10.1038/nature10754

Cragg, S. J. (2006). Meaningful silences: how dopamine listens to the ACh pause. Trends Neurosci. 29, 125-131. doi: 10.1016/j.tins.2006.01.003

D’Ardenne, K., McClure, S. M., Nystrom, L. E., and Cohen, J. D. (2008). BOLD responses reflecting dopaminergic signals in the human ventral tegmental area. Science 319, 1264-1267. doi: 10.1126/science.1150605

Dal Bo, G., St-Gelais, F., Danik, M., Williams, S., Cotton, M., and Trudeau, L.-E. (2004). Dopamine neurons in culture express VGLUT2 explaining their capacity to release glutamate at synapses in addition to dopamine. J. Neurochem. 88, 1398-1405. doi: 10.1046/j.1471-4159.2003.02277.x

Dautan, D., Huerta-Ocampo, I., Witten, I. B., Deisseroth, K., Bolam, J. P., Gerdjikov, T., et al. (2014). A major external source of cholinergic innervation of the striatum and nucleus accumbens originates in the brainstem. J. Neurosci. 34, 4509-4518. doi: 10.1523/JNEUROSCI.5071-13.2014

DeLong, M. R., and Wichmann, T. (2007). Circuits and circuit disorders of the basal ganglia. Arch. Neurol. 64, 20-24. doi: 10.1001/archneur.64.1.20

Descarries, L., Gisiger, V., and Steriade, M. (1997). Diffuse transmission by acetylcholine in the CNS. Prog. Neurobiol. 53, 603-625. doi: 10.1016/s03010082(97)00050-6

Descarries, L., and Mechawar, N. (2000). Ultrastructural evidence for diffuse transmission by monoamine and acetylcholine neurons of the central nervous system. Prog. Brain Res. 125, 27-47. doi: 10.1016/s0079-6123(00)25005-x

Desce, J. M., Godeheu, G., Galli, T., Artaud, F., Chéramy, A., and Glowinski, J. (1992). L-glutamate-evoked release of dopamine from synaptosomes of the rat striatum: involvement of AMPA and N-methyl-D-aspartate receptors. Neuroscience 47, 333-339. doi: 10.1016/0306-4522(92)90249-2

Exley, R., Clements, M. A., Hartung, H., McIntosh, J. M., and Cragg, S. J. (2008). Alpha6-containing nicotinic acetylcholine receptors dominate the nicotine control of dopamine neurotransmission in nucleus accumbens. Neuropsychopharmacology 33, 2158-2166. doi: 10.1038/sj.npp.1301617

Exley, R., and Cragg, S. J. (2008). Presynaptic nicotinic receptors: a dynamic angic filter of striatal dopamine neurotransmission. Br. J. Pharmacol. 153(Suppl.), S283-S297. doi: 10.1038/sj.bjp.0707510

Exley, R., Maubourguet, N., David, V., Eddine, R., Evrard, A., Pons, S., et al. (2011). Distinct contributions of nicotinic acetylcholine receptor subunit alpha4 and subunit alpha6 to the reinforcing effects of nicotine. Proc. Natl. Acad. Sci. US A 108, 7577-7582. doi: 10.1073/pnas.1103000108

Exley, R., McIntosh, J. M., Marks, M. J., Maskos, U., and Cragg, S. J. (2012). Striatal $\alpha 5$ nicotinic receptor subunit regulates dopamine transmission in dorsal striatum. J. Neurosci. 32, 2352-2356. doi: 10.1523/JNEUROSCI.4985-11.2012

Ford, C. P. (2014). The role of D2-autoreceptors in regulating dopamine neuron activity and transmission. Neuroscience doi: 10.1016/j.neuroscience.2014.01. 025. [Epub ahead of print].

Fuxe, K., Borroto-Escuela, D. O., Romero-Fernandez, W., Diaz-Cabiale, Z., Rivera, A., Ferraro, L., et al. (2012). Extrasynaptic neurotransmission in the modulation of brain function. Focus on the striatal neuronal-glial networks. Front. Physiol. 3:136. doi: 10.3389/fphys.2012.00136

Giorguieff, M. F., Le Floc'h, M. L., Glowinski, J., and Besson, M. J. (1977). Involvement of cholinergic presynaptic receptors of nicotinic and muscarinic types in the control of the spontaneous release of dopamine from striatal dopaminergic terminals in the rat. J. Pharmacol. Exp. Ther. 200, 535-544.
Giorguieff, M. F., Le Floc'h, M. L., Westfall, T. C., Glowinski, J., and Besson, M. J. (1976). Nicotinic effect of acetylcholine on the release of newly synthesized $[3 \mathrm{H}]$ dopamine in rat striatal slices and cat caudate nucleus. Brain Res. 106, 117131. doi: 10.1016/0006-8993(76)90077-9

Grace, A., and Bunney, B. (1984a). The control of firing pattern in nigral dopamine neurons: single spike firing. J. Neurosci. 4, 2866-2876.

Grace, A., and Bunney, B. (1984b). The control of firing pattern in nigral dopamine neurons: burst firing. J. Neurosci. 4, 2877-2890.

Groenewegen, H. J. (2003). The basal ganglia and motor control. Neural Plast. 10, 107-120. doi: 10.1155/np.2003.107

Henny, P., Brown, M. T. C., Northrop, A., Faunes, M., Ungless, M. A., Magill, P. J., et al. (2012). Structural correlates of heterogeneous in vivo activity of midbrain dopaminergic neurons. Nat. Neurosci. 15, 613-619. doi: 10.1038/nn.3048

Higley, M. J., Gittis, A. H., Oldenburg, I. A., Balthasar, N., Seal, R. P., Edwards, R. H., et al. (2011). Cholinergic interneurons mediate fast VGluT3-dependent glutamatergic transmission in the striatum. PLoS One 6:e19155. doi: 10 1371/journal.pone.0019155

Hnasko, T. S., Chuhma, N., Zhang, H., Goh, G. Y., Sulzer, D., Palmiter, R. D., et al. (2010). Vesicular glutamate transport promotes dopamine storage and glutamate corelease in vivo. Neuron 65, 643-656. doi: 10.1016/j.neuron.2010. 02.012

Imperato, A., Honoré, T., and Jensen, L. H. (1990). Dopamine release in the nucleus caudatus and in the nucleus accumbens is under glutamatergic control through non-NMDA receptors: a study in freely-moving rats. Brain Res. 530, 223-228. doi: 10.1016/0006-8993(90)91286-p

Jones, I. W., Bolam, J. P., and Wonnacott, S. (2001). Presynaptic localisation of the nicotinic acetylcholine receptor beta2 subunit immunoreactivity in rat nigrostriatal dopaminergic neurones. J. Comp. Neurol. 439, 235-247. doi: 10. 1002/cne. 1345

Joshua, M., Adler, A., and Bergman, H. (2009). The dynamics of dopamine in control of motor behavior. Curr. Opin. Neurobiol. 19, 615-620. doi: 10.1016/j. conb.2009.10.001

Joyce, M. P., and Rayport, S. (2000). Mesoaccumbens dopamine neuron synapses reconstructed in vitro are glutamatergic. Neuroscience 99, 445-456. doi: 10 . 1016/s0306-4522(00)00219-0

Kawagoe, K. T., Garris, P. A., Wiedemann, D. J., and Wightman, R. M. (1992). Regulation of transient dopamine concentration gradients in the microenvironment surrounding nerve terminals in the rat striatum. Neuroscience 51, 55-64. doi: 10 . 1016/0306-4522(92)90470-m

Krebs, M. O., Desce, J. M., Kemel, M. L., Gauchy, C., Godeheu, G., Cheramy, A., et al. (1991). Glutamatergic control of dopamine release in the rat striatum: evidence for presynaptic N-Methyl-D-aspartate receptors on dopaminergic nerve terminals. J. Neurochem. 56, 81-85. doi: 10.1111/j.1471-4159.1991.tb02565.x

Kreitzer, A. C., and Berke, J. D. (2011). Investigating striatal function through cell-type-specific manipulations. Neuroscience 198, 19-26. doi: 10.1016/j. neuroscience.2011.08.018

Kulagina, N. V., Zigmond, M. J., and Michael, A. C. (2001). Glutamate regulates the spontaneous and evoked release of dopamine in the rat striatum. Neuroscience 102, 121-128. doi: 10.1016/s0306-4522(00)00480-2

Le Novère, N., Corringer, P.-J., and Changeux, J.-P. (2002). The diversity of subunit composition in nAChRs: evolutionary origins, physiologic and pharmacologic consequences. J. Neurobiol. 53, 447-456. doi: 10.1002/neu.10153

Limberger, N., Trout, S. J., Kruk, Z. L., and Starke, K. (1991). "Real time" measurement of endogenous dopamine release during short trains of pulses in slices of rat neostriatum and nucleus accumbens: role of autoinhibition. Naunyn Schmiedebergs Arch. Pharmacol. 344, 623-629.

Martin, K. A. C., and Spühler, I. A. (2013). The fine structure of the dopaminergic innervation of area 10 of macaque prefrontal cortex. Eur. J. Neurosci. 37, 10611071. doi: 10.1111/ejn.12124

Matsuda, W., Furuta, T., Nakamura, K. C., Hioki, H., Fujiyama, F., Arai, R., et al. (2009). Single nigrostriatal dopaminergic neurons form widely spread and highly dense axonal arborizations in the neostriatum. J. Neurosci. 29, 444-453. doi: 10.1523/jneurosci.4029-08.2009

Money, K. M., and Stanwood, G. D. (2013). Developmental origins of brain disorders: roles for dopamine. Front. Cell. Neurosci. 7:260. doi: 10.3389/fncel. 2013.00260

Morris, G., Arkadir, D., Nevet, A., Vaadia, E., and Bergman, H. (2004). Coincident but distinct messages of midbrain dopamine and striatal tonically active neurons. Neuron 43, 133-143. doi: 10.1016/j.neuron.2004.06.012 
Moss, J., and Bolam, J. P. (2008). A dopaminergic axon lattice in the striatum and its relationship with cortical and thalamic terminals. J. Neurosci. 28, 11221-11230. doi: 10.1523/jneurosci.2780-08.2008

Moss, J., Ungless, M. A., and Bolam, J. P. (2011). Dopaminergic axons in different divisions of the adult rat striatal complex do not express vesicular glutamate transporters. Eur. J. Neurosci. 33, 1205-1211. doi: 10.1111/j.1460-9568.2011. 07594.x

Nieh, E. H., Kim, S.-Y., Namburi, P., and Tye, K. M. (2013). Optogenetic dissection of neural circuits underlying emotional valence and motivated behaviors. Brain Res. 1511, 73-92. doi: 10.1016/j.brainres.2012.11.001

O’Neill, R. D., and Fillenz, M. (1985). Simultaneous monitoring of dopamine release in rat frontal cortex, nucleus accumbens and striatum: effect of drugs, circadian changes and correlations with motor activity. Neuroscience 16, 49-55. doi: 10.1016/0306-4522(85)90046-6

Paquet, M., and Smith, Y. (2003). Group I metabotropic glutamate receptors in the monkey striatum: subsynaptic association with glutamatergic and dopaminergic afferents. J. Neurosci. 23, 7659-7669.

Patel, J., Trout, S. J., and Kruk, Z. L. (1992). Regional differences in evoked dopamine efflux in brain slices of rat anterior and posterior caudate putamen. Naunyn Schmiedebergs Arch. Pharmacol. 346, 267-276. doi: 10.1007/bf00173539

Pickel, V. M., Beckley, S. C., Joh, T. H., and Reis, D. J. (1981). Ultrastructural immunocytochemical localization of tyrosine hydroxylase in the neostriatum. Brain Res. 225, 373-385. doi: 10.1016/0006-8993(81)90843-x

Rapier, C., Lunt, G. G., and Wonnacott, S. (1990). Nicotinic modulation of $[3 \mathrm{H}]$ dopamine release from striatal synaptosomes: pharmacological characterisation. J. Neurochem. 54, 937-945. doi: 10.1111/j.1471-4159.1990.tb02341.x

Rice, M. E., and Cragg, S. J. (2008). Dopamine spillover after quantal release: rethinking dopamine transmission in the nigrostriatal pathway. Brain Res. Rev. 58, 303-313. doi: 10.1016/j.brainresrev.2008.02.004

Rice, M. E., and Cragg, S. J. (2004). Nicotine amplifies reward-related dopamine signals in striatum. Nat. Neurosci. 7, 583-584. doi: 10.1038/nn1244

Rice, M. E., Patel, J. C., and Cragg, S. J. (2011). Dopamine release in the basal ganglia. Neuroscience 198, 112-137. doi: 10.1016/j.neuroscience.2011.08.066

Schiemann, J., Schlaudraff, F., Klose, V., Bingmer, M., Seino, S., Magill, P. J., et al. (2012). K-ATP channels in dopamine substantia nigra neurons control bursting and novelty-induced exploration. Nat. Neurosci. 15, 1272-1280. doi: 10. 1038/nn.3185

Schmitz, Y., Benoit-Marand, M., Gonon, F., and Sulzer, D. (2003). Presynaptic regulation of dopaminergic neurotransmission. J. Neurochem. 87, 273-289. doi: 10.1046/j.1471-4159.2003.02050.x

Schultz, W. (1998). Predictive reward signal of dopamine neurons. J. Neurophysiol. $80,1-27$.

Schultz, W. (2007a). Behavioral dopamine signals. Trends Neurosci. 30, 203-210. doi: 10.1016/j.tins.2007.03.007

Schultz, W. (2007b). Multiple dopamine functions at different time courses. Annu. Rev. Neurosci. 30, 259-288. doi: 10.1146/annurev.neuro.28.061604.135722

Schultz, W. (2013). Updating dopamine reward signals. Curr. Opin. Neurobiol. 23, 229-238. doi: 10.1016/j.conb.2012.11.012

Schultz, W., Dayan, P., and Montague, P. R. (1997). A neural substrate of prediction and reward. Science 275, 1593-1599. doi: 10.1126/science.275.5306.1593

Segovia, G., Del Arco, A., and Mora, F. (1997). Endogenous glutamate increases extracellular concentrations of dopamine, GABA and taurine through NMDA and AMPA/kainate receptors in striatum of the freely moving rat: a microdialysis study. J. Neurochem. 69, 1476-1483. doi: 10.1046/j.1471-4159.1997.69041476.x

Sesack, S. R., and Grace, A. A. (2010). Cortico-basal ganglia reward network: microcircuitry. Neuropsychopharmacology 35, 27-47. doi: 10.1038/npp.2009.93

Shimo, Y., and Hikosaka, O. (2001). Role of tonically active neurons in primate caudate in reward-oriented saccadic eye movement. J. Neurosci. 21, 7804-7814.

Smith, Y., Bennett, B. D., Bolam, J. P., Parent, A., and Sadikot, A. F. (1994). Synaptic relationships between dopaminergic afferents and cortical or thalamic input in the sensorimotor territory of the striatum in monkey. J. Comp. Neurol. 344, 119. doi: $10.1002 / \mathrm{cne} .903440102$

Stuber, G. D., Britt, J. P., and Bonci, A. (2012). Optogenetic modulation of neural circuits that underlie reward seeking. Biol. Psychiatry 71, 1061-1067. doi: 10. 1016/j.biopsych.2011.11.010

Stuber, G. D., Hnasko, T. S., Britt, J. P., Edwards, R. H., and Bonci, A. (2010). Dopaminergic terminals in the nucleus accumbens but not the dorsal striatum corelease glutamate. J. Neurosci. 30, 8229-8233. doi: 10.1523/JNEUROSCI.175410.2010
Sulzer, D., Joyce, M. P., Lin, L., Geldwert, D., Haber, S. N., Hattori, T., et al. (1998). Dopamine neurons make glutamatergic synapses in vitro. J. Neurosci. 18, 45884602 .

Sulzer, D., and Rayport, S. (2000). Dale's principle and glutamate corelease from ventral midbrain dopamine neurons. Amino Acids 19, 45-52. doi: 10. 1007/s007260070032

Taber, K. H., and Hurley, R. A. (2014). Volume transmission in the brain: beyond the synapse. J. Neuropsychiatry Clin. Neurosci. 26,iv, 1-4. doi: 10.1176/appi. neuropsych.13110351

Threlfell, S., Clements, M. A., Khodai, T., Pienaar, I. S., Exley, R., Wess, J., et al. (2010). Striatal muscarinic receptors promote activity dependence of dopamine transmission via distinct receptor subtypes on cholinergic interneurons in ventral versus dorsal striatum. J. Neurosci. 30, 3398-3408. doi: 10.1523/jneurosci. 5620-09.2010

Threlfell, S., and Cragg, S. J. (2011). Dopamine signaling in dorsal versus ventral striatum: the dynamic role of cholinergic interneurons. Front. Syst. Neurosci. 5:11. doi: $10.3389 /$ fnsys.2011.00011

Threlfell, S., Lalic, T., Platt, N. J., Jennings, K. A., Deisseroth, K., and Cragg, S. J. (2012). Striatal dopamine release is triggered by synchronized activity in cholinergic interneurons. Neuron 75, 58-64. doi: 10.1016/j.neuron.2012. 04.038

Tremblay, L., Kemel, M. L., Desban, M., Gauchy, C., and Glowinski, J. (1992). Distinct presynaptic control of dopamine release in striosomal- and matrixenriched areas of the rat striatum by selective agonists of NK1, NK2 and NK3 tachykinin receptors. Proc. Natl. Acad. Sci. U S A 89, 11214-11218. doi: 10. 1073/pnas.89.23.11214

Tritsch, N. X., and Sabatini, B. L. (2012). Dopaminergic modulation of synaptic transmission in cortex and striatum. Neuron 76, 33-50. doi: 10.1016/j.neuron. 2012.09.023

Van Bockstaele, E. J., and Pickel, V. M. (1995). GABA-containing neurons in the ventral tegmental area project to the nucleus accumbens in rat brain. Brain Res. 682, 215-221. doi: 10.1016/0006-8993(95)00334-m

Voorn, P., Vanderschuren, L. J. M. J., Groenewegen, H. J., Robbins, T. W., and Pennartz, C. M. A. (2004). Putting a spin on the dorsal-ventral divide of the striatum. Trends Neurosci. 27, 468-474. doi: 10.1016/j.tins.2004. 06.006

Wilson, C. J., Chang, H. T., and Kitai, S. T. (1990). Firing patterns and synaptic potentials of identified giant aspiny interneurons in the rat neostriatum. $J$. Neurosci. 10, 508-519.

Wonnacott, S., Irons, J., Rapier, C., Thorne, B., and Lunt, G. G. (1989). Presynaptic modulation of transmitter release by nicotinic receptors. Prog. Brain Res. 79, 157-163. doi: 10.1016/s0079-6123(08)62475-9

Wu, Y., Pearl, S. M., Zigmond, M. J., and Michael, A. C. (2000). Inhibitory glutamatergic regulation of evoked dopamine release in striatum. Neuroscience 96, 65-72. doi: 10.1016/s0306-4522(99)00539-4

Yan, Z., and Surmeier, D. J. (1996). Muscarinic (m2/m4) receptors reduce N- and P-type Ca2+ currents in rat neostriatal cholinergic interneurons through a fast, membrane-delimited, G-protein pathway. J. Neurosci. 16, 2592-2604.

Zhang, H., and Sulzer, D. (2003). Glutamate spillover in the striatum depresses dopaminergic transmission by activating group I metabotropic glutamate receptors. J. Neurosci. 23, 10585-10592.

Zhang, H., and Sulzer, D. (2012). Regulation of striatal dopamine release by presynaptic auto- and heteroreceptors. Basal Ganglia 2, 5-13. doi: 10.1016/j. baga.2011.11.004

Conflict of Interest Statement: The authors declare that the research was conducted in the absence of any commercial or financial relationships that could be construed as a potential conflict of interest.

Received: 02 March 2014; accepted: 07 May 2014; published online: 23 May 2014. Citation: Cachope R and Cheer JF (2014) Local control of striatal dopamine release. Front. Behav. Neurosci. 8:188. doi: 10.3389/fnbeh.2014.00188

This article was submitted to the journal Frontiers in Behavioral Neuroscience. Copyright (c) 2014 Cachope and Cheer. This is an open-access article distributed under the terms of the Creative Commons Attribution License (CC BY). The use, distribution or reproduction in other forums is permitted, provided the original author (s) or licensor are credited and that the original publication in this journal is cited, in accordance with accepted academic practice. No use, distribution or reproduction is permitted which does not comply with these terms. 